\title{
Encefalitis límbica por anticuerpos anticanales de potasio dependientes de voltaje. Caso clínico
}

\author{
Bernardita Soler, Jaime G odoy, Patricio Mellado
}

Limbic encephalitis associated to voltage dependent potassium channel antibodies. Report of one case

Limbic encephalitis (LE) can be associated to cancer, viral infection or be idiopathic. One form is associated to voltage dependent potassium channel (VKC) antibodies. The clinical presentation includes impairment of consciousness, amnesia and temporal lobe seizures; typical abnormalities are also found in brain magnetic resonance. We report a 68 year-old male who had LE associated to VKC antibodies. The patient was treated with steroids with a partial response. At the moment of the report he is asymptomatic and continues with prednisone treatment (Rev Méd Chile 2009; 137: 675-9).

(Key words: Autoantibodies; Limbic encephalitis; Potassium channels, voltage-gated)

Recibido el 22 de agosto, 2008. Aceptado el 15 de diciembre, 2008.

Departamento de Neurología, Escuela de Medicina, Pontificia Universidad Católica de Chile.

$\mathrm{L}$ a encefalitis límbica (EL) fue descrita en 1960 por Brierley et al, los que comunicaron tres pacientes con encefalitis subaguda que afectaba principalmente la región límbica ${ }^{1}$. El año 1968 Corsellis et al acuñaron el nombre de EL y la caracterizaron como una enfermedad autoinmu$\mathrm{ne}^{2}$. Actualmente se le reconoce como un síndrome paraneoplásico, en el que el tumor provoca una respuesta inmunológica cruzada contra las estructuras límbicas. En la última década se han descrito dos nuevas etiologías de EL, la secundaria a infección herpética, que puede afectar tanto a inmunocompetentes (virus herpes simple 1) como inmunocomprometidos (virus herpes simple 2, 6 y $7^{3,4}$, y la idiopática 0 autoinmune, variedad

Correspondencia a: Dr. Patricio Mellado Talesnik. Marcoleta 352, Santiago Chile. Teléfono: 3543316.

E mail: pmellado@med.puc.cl potencialmente reversible y probablemente mediada por anticuerpos, entre los que destacan los anticanales de potasio dependientes de voltaje (anticuerpos anti-ckvd) $)^{5}$. La EL por virus herpes no debe ser confundida con la encefalitis herpética, la que tiene caracteres clínicos, radiológicos e histopatológicos distintos.

\section{CASO CLÍNICO}

Hombre de 68 años con antecedentes de hipertensión arterial crónica, dislipidemia y reflujo gastroesofágico en tratamiento. Un mes antes de su ingreso había presentado una convulsión tónicoclónica generalizada, sin elementos clínicos sugerentes de inicio focal, que había sido estudiada con resonancia magnética (RM) de encéfalo y electroencefalograma (EEG) que resultaron negativos, después de lo cual empezó a recibir fenitoína 400 $\mathrm{mg} /$ día. Dos semanas después comenzó a presen- 
tar episodios repetidos de angustia, dificultad para hablar, alucinaciones visuales y olfatorias y temblor de extremidades superiores de segundos de duración, que motivaron su hospitalización.

El examen físico general de ingreso fue normal y el examen neurológico sólo pesquisó un paciente bradipsíquico.

En los exámenes de laboratorio destacó la presencia de hiponatremia (122 meq/l) con volumen circulante efectivo normal, que mejoró con restricción de agua por lo que se diagnosticó un síndrome de secreción inapropiada de hormona antidiurética (SSIADH). El estudio reumatológico completo fue normal. Se realizó una RM de encéfalo que mostró hiperintensidad de señal en las secuencias T2 y FLAIR en ambos hipocampos, con leve aumento de volumen del hipocampo izquierdo (Figura 1). El líquido cefalorraquídeo mostró celularidad normal, discreta elevación de proteínas $(43 \mathrm{mg} / \mathrm{dl})$, ausencia de bandas oligoclonales, índice de albúmina/IgG y citometría de flujo normales y PCR para virus herpes simple negativo.

Por presentar episodios recurrentes de angustia de inicio y término ictales, asociados a afasia o parafasias y alucinaciones visuales se solicitó un EEG que documentó 3 crisis electroclínicas originadas en el lóbulo temporal izquierdo, diagnosticándose un estado epiléptico focal (Figura 2A),

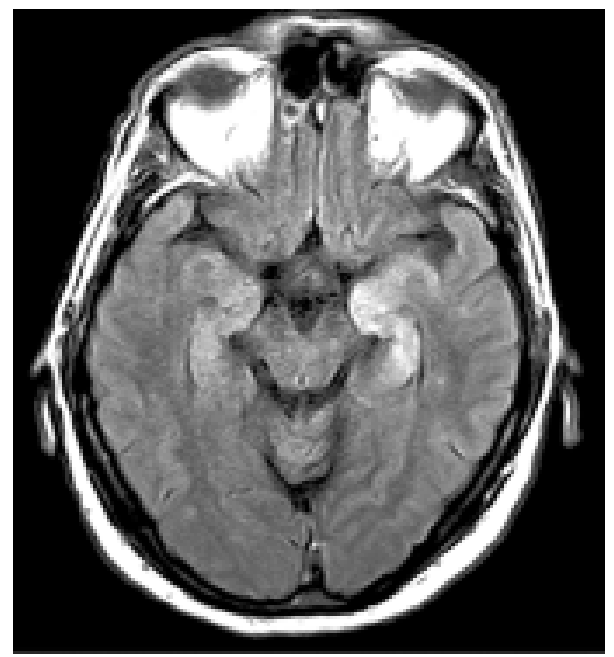

Figura 1. Secuencia FLAIR de RM, muestra hiperintensidad de ambos lóbulos temporales en forma asimétrica, mayor a izquierda. por lo que se agregó levetiracetam $(1 \mathrm{~g} \mathrm{c} / 8 \mathrm{~h})$ y se optimizó la dosis de fenitoína hasta obtener niveles plasmáticos libres de $2 \mathrm{ug} / \mathrm{ml}$. El paciente mantuvo su condición por lo que se agregó ácido valproico intravenoso en carga $(20 \mathrm{mg} / \mathrm{kg})$, sin obtener respuesta. Se suspendió la fenitoína y se agregó topiramato (200 mg c/12 h) y clobazam (20 mg/noche), con lo que se controló por completo la actividad epileptiforme en $48 \mathrm{~h}$. Los EEGs sucesivos mostraron sólo lentitud difusa, mayor a nivel temporal izquierdo (Figura 2B) y,

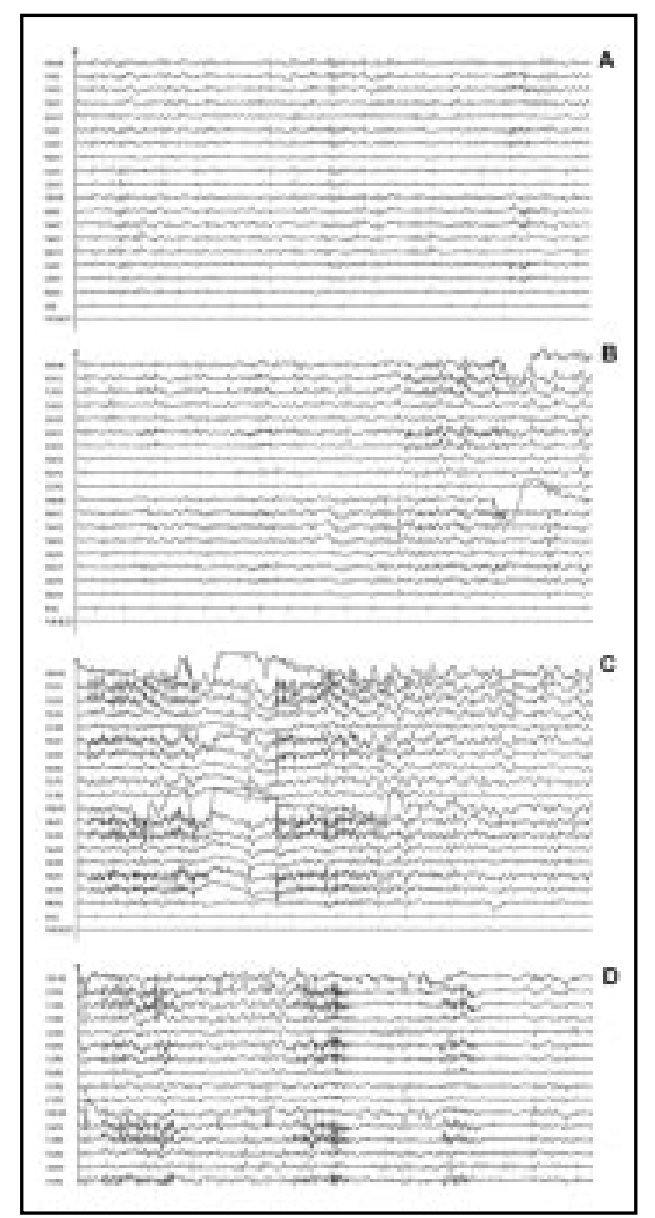

Figura 2. Registro de crisis electroclínicas. Paciente somnoliento (A), en el que aparece patrón de reclutamiento ictal de inicio temporal anterior y medio izquierdo (B), con dispersión frontal (C) y término brusco (D). Durante el episodio el paciente presentó claro trastorno del lenguaje. Estos eventos recurrieron de modo subintrante. 
desde el punto de vista clínico, no presentó nuevos episodios de angustia ni alucinaciones.

La tomografía computarizada de tórax, abdomen y pelvis y la ecografía testicular fueron normales. La RM de encéfalo de control mostró persistencia de la hiperintensidad temporal bilateral, se planteó el diagnóstico de EL. Se solicitó estudio de anticuerpos anti-ckvd fuera del país y se inició terapia con esteroides en forma empírica (metilprednisolona $1 \mathrm{gr} /$ día por 5 días consecutivos), con lo que se observó una respuesta parcial. El paciente evolucionó con episodios más prolongados de conexión con su entorno e inatento; fue dado de alta al decimoquinto día con un síndrome confusional en resolución y con EEG sin actividad epileptiforme.

El resultado del estudio de anticuerpos antickvd resultó positivo, confirmando el diagnóstico de EL Actualmente el paciente se encuentra asintomático, con EEG de control normal y completamente autovalente. Se mantiene en tratamiento con ácido valproico $500 \mathrm{mg} \mathrm{c} / 8 \mathrm{~h}$, levetiracetam $1,5 \mathrm{~g} \mathrm{c} / 12 \mathrm{~h}$ y prednisona $20 \mathrm{mg}$, día por medio.

\section{DISCUSIÓN}

El cuadro clínico de la EL se caracteriza por la aparición subaguda de déficit neuropsicológico, amnesia anterógrada, alteración de memoria reciente, tendencia a la fabulación, convulsiones, síndrome confusional, pudiendo llegar a sopor y coma. La tomografía computarizada de encéfalo es habitualmente normal. La RM de encéfalo en $70 \%$ de los casos muestra una alteración, característicamente una hiperintensidad asimétrica de los lóbulos temporales, especialmente en las secuencias de FLAIR y T2 ${ }^{6-8}$, si bien se han reportado pacientes con EL que presentan una RM normal $(30 \%)^{8}$, éstos presentan alteraciones características en la tomografía por emisión de positrones, donde se observa hipermetabolismo en el hipocampo $^{9}$. El EEG muestra una lentitud temporal o difusa, espigas temporales, crisis eléctricas o estado epiléptico, focal temporal o generalizado ${ }^{10,11}$. En la mayoría de los casos el líquido cefalorraquídeo muestra elementos inflamatorios discretos, sin hallazgos patognomónicos ${ }^{5}$ y en $30 \%$ hay SSIADH asociado $^{12}$. Las primeras descripciones anatomopatológicas fueron realizadas a partir de material obtenido de resecciones del lóbulo temporal de pacientes con epilepsias intratables ${ }^{13}$. En el estudio histopatológico se observa un infiltrado linfocitario perivascular y parenquimatoso, nódulos microgliales, gliosis y pérdida neuronal en la sustancia gris del hipocampo, giro cingulado, corteza piriforme y órbito frontal, ínsula y núcleos amigdalinos ${ }^{13}$.

Actualmente se distinguen 3 variedades de EL 1. Paraneoplásica, asociada principalmente a cáncer de pulmón y menos frecuentemente a linfoma, leucemia, cáncer de cuello uterino, mama, testículo, tiroides 0 teratoma ${ }^{5,14}$, en las que se identifican anticuerpos que presentan algún grado de especificidad respecto a esta neoplasia (Tabla 1); es importante destacar que los síntomas neurológicos pueden preceder al diagnóstico de cáncer en $60 \%$ y $75 \%$ de los $\operatorname{casos}^{5,15}$. 2. Virales, especialmente virus herpes simple 1 en inmunocompetentes y virus herpes simple 2, 6 y 7 en inmunocomprometidos y, 3. Idiopática, subgrupo en el que se incluye la forma asociada a anticuerpos anti-ckvd ${ }^{4,5}$, que se ha descrito también asociada a cáncer, especialmente

Tabla 1. Asociación entre anticuerpos, encefalitis límbica y cáncer ${ }^{4,7}$.

\begin{tabular}{|ll|}
\hline Anticuerpo & Cáncer \\
\hline Anti-Hu & Células pequeñas de pulmón \\
Anti Ma (Ma 2, Ma 1) & Testículo/No-células pequeñas de pulmón \\
Anti-CV2/CRMP5 & Células pequeñas pulmón/timoma \\
NMDAR & Ovario/teratoma \\
Neuropilo & Timoma/células pequeñas de pulmón \\
Antianfifisina & Mama/células pequeñas de pulmón \\
ANNA-3 & Células pequeñas de pulmón \\
\hline
\end{tabular}


pulmón y timoma ${ }^{14}$. Se estima que una EL puede ser considerada idiopática si se documentan estudios negativos para cáncer por un período de 5 años ${ }^{16}$.

Nuestro paciente cumple con las características de una EL, presentó un cuadro confusional, un estado epiléptico focal temporal y tenía alteraciones hipocampales bilaterales en la RM. En relación a la etiología, se descartó razonablemente una neoplasia y se demostró la presencia de anticuerpos anti-ckvd. Además, como ocurre en un tercio de estos pacientes ${ }^{6}$, presentó hiponatremia, la que se comportó como un SSIADH. Para asegurar la ausencia de neoplasia falta completar el periodo de observación de 5 años.

La EL idiopática es causada por una respuesta inmune anómala que daña las neuronas del sistema límbico. En el caso de la asociada a anticuerpos anti-ckvd se ha postulado que estos anticuerpos son responsables directos del daño neuronal. Esta hipótesis es avalada por la mejoría del cuadro al utilizar tratamiento inmunosupresor, inmunomodulador o plasmaféresis, donde se ha observado, en algunos casos, una drástica disminución de los niveles de anticuerpo y mejoría de la clínica en forma proporcional a este descenso ${ }^{17}$. Los anticuerpos anti-ckvd van dirigidos contra los subtipos de canal de potasio $\mathrm{Kv} 1.1, \mathrm{Kv}$ 1.2 y Kv $1.6^{6,7}$, localizados principalmente en la superficie de la membrana citoplasmática de neuronas del giro dentado. En cambio, existen otros anticuerpos que reconocen antígenos intraneuronales, entre los que destaca el anti-Hu. Estos anticuerpos efectivamente pueden constituir un epifenómeno y sólo ser marcadores de una respuesta inmune contra otro antígeno neuronal, cuyo anticuerpo es desconocido, o ser patogénicos a nivel intraneuronal, lo cual explicaría la ausencia de respuesta con tratamiento inmunomodulador, plasmaféresis e inmunoglobulina, los que

\section{REFERENCIAS}

1. Brierley JB, Corsewis JAN, Hierons R, Nevin S. Subacute encephalitis of later adult life. Mainly affecting the limbic areas. Brain 1960; 83: 357-68.

2. Corselus JAN, Goldberg GJ, Norton AR Limbic encephalitis and its association with carcinoma. Brain 1968; 91: 481-96.

3. KenNEDy PG. Viral encephalitis. J Neurol 2005; 252: 268-72. no lograrían modificar su efecto a nivel intraneuronal. En el estudio de Dalmau et al, 82\% de los casos con EL no viral presentaron anticuerpos contra proteínas del sistema nervioso central ${ }^{8}$.

El tratamiento de elección recomendado en la EL secundaria a anticuerpos anti-ckvd, son los pulsos de esteroides intravenosos ${ }^{8}$, terapia utilizada en nuestro paciente. Otras alternativas terapéuticas son la plasmaféresis y la inmunoglobulina intravenosa, en dosis similares a las usadas en otras patologías neurológicas de etiología autoinmune, como el síndrome de Guillain Barré, crisis miasténica o encefalomielitis diseminada aguda ${ }^{17}$.

Existen otros síndromes relacionados con los anticuerpos anti-ckvd, pero que comprometen al sistema nervioso periférico como los síndromes de Morvan e Isaac y una variedad de polineuropatía autonómica ${ }^{18,19}$. El tratamiento de la EL se orienta a controlar los síntomas, especialmente las crisis epilépticas y en los casos en que se detecta una etiología, debe implementarse un tratamiento específico o inmunomodulación. Se recomienda usar monitorización continua electroencefalográfica para evaluar el control de las crisis convulsivas ya que muchas de ellas son subclínicas o sutiles ${ }^{20}$.

\section{CONCLUSIÓN}

La EL es un cuadro probablemente subdiagnosticado, que debe tenerse presente en el diagnóstico diferencial de cuadros confusionales de instalación subaguda.

Una vez establecido este diagnóstico, corresponde descartar la presencia de neoplasia y, de ser este estudio negativo, investigar la presencia de anticuerpos anti-ckvd, como se diera en este primer caso de EL identificado con verificación de este anticuerpo reportado en Chile.

4. WhITLEY RJ, GNANN JW. Viral encephalitis: familiar infections and emerging pathogens. Lancet 2002; 359: 507-13.

5. Sснотт J. Limbic encephalitis: a clinican's guide. Pract Neurol 2006; 6: 143-53.

6. TÜZum E, DaLmaU J. Limbic encephalitis and variant: Classification, diagnosis and treatment. The Neurologist 2007; 13: 261-71.

7. ANDERSON NE, BARBER PA. Limbic encephalitis a review. J Clin Neurosci 2008, http: //www.sciencedirect.com/ 
science? ob=Mlmg\& imagekey=B6WHP-4S8TR8K47.

8. Dalmau J $\bar{J}$ Bataler $L$. Encefalitis límbica: los nuevos antígenos de membrana y propuesta de nueva clasificación clínico inmunológica con implicaciones terapéuticas. Neurología 2007; 22: 526-37.

9. FaKhoury T, Abou-Khall B, Kessler RM. Limbic encephalitis and hyperactive foci on PET scan. Seizure 1999; 8: 427-31.

10. Mcknight K, Jiang Y, Hart Y, Cavey A, Wroe S, Black M. Serum antibodies in epilepsy and seizure-associated disorders. Neurology 2005; 65: 1730-6.

11. Wieser S, Kelemen A, Barsi P, Vincent A, Borbely C, RAsonyi G ET aL. Pilomotor seizures and status in non-paraneoplastic limbic encephalitis. Epileptic Disord 2005; 7: 205-11.

12. Prats JM, Gaztañaga R, Palacio M. Encefalitis límbica no paraneoplásica. Rev Neurol 2003; 36: 335-7.

13. BaKheit AMO, Kennedy PGE, Behan PO. Paraneoplastic limbic encephalitis: clinico pathological correlations. J Neurol Neurosurg Psychiatry 1990; 53: 1084-8.

14. Tan K, Lennon V, Kiein C, Boeve B, Pittock SJ. Clinical spectrum of voltage - gated potassium channel autoimmunity. Neurology 2008; 70: 1883-90.
15. Gultekin SH, Rosenfeld MR, Voltz R, Eichen J, Posner JB, Dalmau J. Paraneoplastic limbic encephalitis: neurological symptoms, immunological findings and tumour association in 50 patients. Brain 2000; 123: 1481-94.

16. Graus F, Saiz A. Limbic encephalitis. An expanding concept. Neurology 2008; 70: 500-1.

17. Vincent A, Buckiey C, Schott JM, BaKer I, Dewar BK, DETERT N. Potassium channel antibody- associated encephalopathy: a potentially immunotherapy-responsive form of limbic encephalitis. Brain 2004; 127: 701-12.

18. Hart IK, Waters C, Vincent A, Newland C, Beeson D, Pongs $O$ ET AL. Autoantibodies detected to expressed $\mathrm{K}+$ channels are implicated in neuromyotonia. Ann Neurol 1997; 41: 238-46.

19. Barber PA, ANDERson NE, Vincent A. Morvan's syndrome associated with voltage-gated $\mathrm{K}+$ channel antibodies. Neurology 2000; 54: 771-2.

20. Melado P, Godoy J. Monitorización electroencefalográfica continua en la unidad de cuidados intensivos. Cuad Neurol 2006; 30: 151-72. 